\title{
Cinética da fermentação ruminal in vitro de dietas contendo palma forrageira enriquecida com ureia e suplementadas com diferentes fontes de amido
}

\section{In vitro ruminal fermentation kinetic of diets containing forage cactus with urea and different starch sources}

\author{
Yann dos Santos Luz ${ }^{1 *}$; Mauro Pereira de Figueiredo²; Fábio Martins Oliveira ${ }^{1}$; \\ Fernando Salgado Bernardino ${ }^{3}$; Eduardo de Jesus Novaes ${ }^{4}$; \\ João Paulo Santos Roseira ${ }^{4}$
}

\begin{abstract}
Resumo
O presente estudo teve por objetivo avaliar a cinética da fermentação de dietas a base de palma forrageira enriquecida com ureia e feno de capim tifton (85) contendo diferentes fontes de amido, por meio da técnica semi-automática de produção de gases in vitro. Os tratamentos (dietas) foram dispostos em um delineamento em blocos casualizados, com quatro repetições, sendo os concentrados compostos como segue: farelo de soja e raiz de mandioca (FSMa), farelo de soja e milho semiduro (FSMiSD), farelo de trigo e mandioca (FTMa) e farelo de soja e milho dentado (FSMiD). As dietas foram formuladas para obter teores de $15 \%$ de proteína bruta na matéria seca. A pressão dos gases foi mensurada às 2 , $4,6,8,10,12,15,18,21,24,30,36,48,72$ e 96 h após a inoculação. Para o volume de produção de gases dos carboidratos não fibrosos nas primeiras 6 horas de fermentação os tratamentos contendo as duas variedades de milho (FSMiSD e FSMiD) não diferiram entre si $(\mathrm{P}>0,05)$ enquanto que, o FTMa diferiu $(\mathrm{P}<0,05)$ das dietas que continham milho como fonte principal de amido. A taxa específica de degradação da fração rápida (Kd1) foi maior nas dietas compostas por FSMa e FTMa quando comparada às contendo milho. $\mathrm{O}$ tempo de colonização $(\mathrm{L})$ foi menor $(\mathrm{P}<0,05)$ na dieta com FTMa, quando comparado às demais. A produção total de gases foi menor para o tratamento FTMa e maior para o FSMiSD, variando de $225,49 \mathrm{~mL} / \mathrm{g}$ a $268,31 \mathrm{~mL} / \mathrm{g}$, respectivamente. A utilização da mandioca como fonte de amido proporciona uma fermentação mais rápida, quando comparada ao milho, permitindo melhor sincronização com fontes de nitrogênio de rápida degradação.
\end{abstract}

Palavras-chave: Carboidrato, degradação ruminal, sincronização

\begin{abstract}
The study was conducted to evaluate fermentation kinetic of diets based on cactus forage enriched with urea and Tifton 85 hay, containing different starch sources, using semi-automated in vitro gas production technique. Treatments were disposed in a randomized block design, with four replications,
\end{abstract}

\footnotetext{
${ }^{1}$ Discentes do Curso de Mestrado em Produção Animal, Universidade Estadual do Sudoeste da Bahia, UESB, Itapetinga, BA. E-mail: yann_agronomia@yahoo.com.br; fmo.pc@bol.com.br

${ }^{2}$ Prof. do Dept ${ }^{\circ}$ de Fitotecnia e Zootecnia, UESB, Vitória da Conquista, BA. E-mail: mfigue2@yahoo.com.br

${ }^{3}$ Dr. em Zootecnia, Bolsista de Pós-Doutorado da Fundação de Amparo à Pesquisa do Estado da Bahia, FAPESB, Vitória da Conquista, BA. E-mail: fsbernardino@gmail.com

${ }^{4}$ Discentes do Curso de Graduação em Engenharia Agronômica, UESB, Vitória da Conquista, BA. E-mail: eduardo_tec.agro@ hotmail.com; jpr-santos@hotmail.com

* Autor para correspondência
} 
where concentrates were formulated as follows: cassava roots (FSMa), semi flint corn grains (FSMiSD), dent corn grains (FSMiD) and wheat bran (FTMa). All diets were formulated to obtain $15 \%$ of crude protein. Gas pressure were measured 2, 4, 6, 8, 10, 12, 15, 18, 21, 24, 30, 36, 48, 72 and $96 \mathrm{~h}$ after inoculation. For fast phase maximum gas volume (Vf1), both treatments containing corn did not differ $(\mathrm{P}>0.05)$. FTMa differed $(\mathrm{P}<0.05)$ from diets composed with corn, as main starch source. Specific degradation rate of fast fraction $(\mathrm{Kd} 1)$ was higher $(\mathrm{P}<0.05)$ on FSMa and FTMa diets, compared with corn diets. Colonization time $(\mathrm{L})$ showed lower values $(\mathrm{P}<0.05)$ for FTMa diet. The lowest total gas production was observed on FTMa and the highest for FSMiD, varying from 225.49 to $268.31 \mathrm{~mL} / \mathrm{g}$, respectively. Cassava roots as starch source contributes to a faster fermentation, compared to both corns, allowing a better synchronization with faster degradation nitrogen sources.

Key words: Carbohydrate, ruminal degradation, synchronization

\section{Introdução}

Para a formulação de dietas que apresentem alta eficiência nutricional e econômica, é importante avaliar as fontes de carboidratos e proteínas presentes nos alimentos, que são os principais componentes nutricionais nas dietas para bovinos. A importância destes nutrientes não se resume apenas ao seu efeito dietético individual, mas também à interação entre ambos, que possibilita maior eficiência da atividade microbiana, influenciando a digestibilidade ruminal, a produção de proteína microbiana e, consequentemente, o fluxo de nutrientes do rúmen para o trato digestivo inferior (CALDAS NETO et al., 2007).

Em conformidade com a sua origem, o amido apresenta características próprias na dependência de diversos fatores tais como a fonte vegetal, idade da planta, relação amilose/amilopectina, forma e tamanho dos grânulos. Assim, as propriedades funcionais dos amidos dependem da estrutura molecular dos seus biopolímeros e da forma como eles estão organizados nos grânulos (FREDRIKSSON et al., 1997).

Em dietas a base de alimentos volumosos tratados com ureia e suplementada com concentrados, a sincronização da velocidade de degradação de carboidratos e nitrogênio nas fontes destes nutrientes, deve proporcionar a maximização da eficiência da síntese de proteína microbiana e a diminuição das perdas energia dos carboidratos e de nitrogênio na forma de amônia, promovendo a melhoria na degradabilidade ruminal da matéria seca no rúmen (MOORE et al., 1999; BODINE; PURVIS, 2003).

Neste contexto, a palma forrageira vem sendo utilizada extensivamente nos sistemas de produção animal no semi-árido brasileiro. A mais utilizada para este fim é a palma gigante (Opuntia ficusindica (L.) Mill. cv. Gigante) por ser considerada a mais produtiva e mais resistente às regiões secas conforme Silva e Santos (2006), apresentando um teor protéico que varia de $3,65 \%$ a $5,97 \%$ de acordo com Ferreira et al. (2003) ou seja, insuficiente para atender as necessidades nutricionais de bovinos (NRC 1996; NRC 2001). Ademais, sua utilização in natura na dieta não deve ser exclusiva implicando em decréscimo no consumo e ingestão de nutrientes (SILVA; SANTOS, 2006).

O tratamento da palma com ureia tem sido utilizado com o objetivo de aumentar a contribuição de nitrogênio desta cactácea, possibilitando uma redução no uso de alimentos concentrados protéicos no balanceamento de rações para o gado leiteiro (ALBUQUERQUE et al., 2002). Por outro lado, o aumento do nitrogênio não protéico nas dietas contendo palma tratada com ureia requer o uso de fontes de carboidratos compatíveis com a elevada disponibilidade de amônia resultante da hidrólise deste composto (CALDAS NETO et al., 2007).

Desta forma, objetivou-se neste trabalho avaliar a cinética de fermentação ruminal de diferentes fontes de amido, em dietas contendo palma forrageira tratada com ureia, utilizando a técnica semi-automática de produção de gases in vitro. 


\section{Material e Métodos}

O experimento e as análises laboratoriais foram realizados no Laboratório de Nutrição Animal do Departamento de Fitotecnia e Zootecnia da Universidade Estadual do Sudoeste da Bahia UESB - Campus Vitória da Conquista, BA.

Para a avaliação da cinética de fermentação ruminal in vitro foram formuladas quatro dietas experimentais (Tabela 1), com relação 50:50 volumoso:concentrado (base seca), isonitrogenadas, de modo que todas as dietas continham palma forrageira (Opuntia ficus-indica (L.) Mill. cv.
Gigante) tratadas com $10 \mathrm{~g}$ de ureia/kg de matéria natural e feno de Tifton 85 (Cynodon dactylon). Os tratamentos consistiram no uso de diferentes fontes de amido no concentrado, sendo: raiz de mandioca (Manihot esculenta Crantz. cv. Caetité); milho semiduro (Zea mays cv. AL Bandeirante); milho dentado (Zea mays cv. Ag1051) e farelo de trigo, para as quatro diferentes dietas formuladas no ensaio, sendo os concentrados compostos como segue: farelo de soja e raiz de mandioca (FSMa), farelo de soja e milho semiduro (FSMiSD), farelo de trigo e mandioca (FTMa) e farelo de soja e milho dentado (FSMiD).

Tabela 1. Proporção dos ingredientes ( $\mathrm{g} / \mathrm{kg}$ de matéria seca) e Composição nutricional das dietas experimentais.

\begin{tabular}{lcccc}
\hline \multirow{2}{*}{ Item } & \multicolumn{4}{c}{ Tratamentos $^{1}$} \\
\cline { 2 - 5 } & FSMa & FTMa & FSMiSD & FSMiD \\
\hline Palma enriquecida & 250 & 250 & 250 & 250 \\
Feno de Tifton & 250 & 250 & 250 & 250 \\
Farelo de soja (FS) & 73 & - & 9 & 9 \\
Milho moído (MD) & - & - & - & 491 \\
Milho moído (MSD) & - & - & 491 & - \\
Farelo de trigo (FT) & - & 240 & - & - \\
Mandioca raiz (M) & 427 & 260 & - & - \\
\hline \multicolumn{1}{c}{ Composição $_{\text {Matéria seca }}^{3}$} & & & & 905,2 \\
Matéria mineral $^{4}$ & 916,5 & 904,1 & 56,7 \\
Proteína bruta $^{4}$ & 76,1 & 98,3 & 51,8 & 148,1 \\
Extrato etéreo $^{4}$ & 148,4 & 147,7 & 62,6 & 48,9 \\
FDN $^{4}$ & 36,7 & 31,2 & 372,7 & 379,2 \\
FDNcp $^{4}$ & 302,4 & 391,2 & 344,1 & 345,7 \\
FDA $^{4}$ & 273,9 & 356,7 & 133,2 & 128,5 \\
Lignina $^{4}$ & 144,5 & 167,3 & 49,6 & 41,5 \\
CT $^{4}$ & 44,3 & 51,8 & 738,6 & 736,3 \\
CNF $^{4}$ & 738,8 & 722,8 & 564,6 & 460,7 \\
NDT $^{2,4}$ & 534,9 & 439,1 & 751,9 & 725,8 \\
\hline
\end{tabular}

${ }^{1}$ FSMa: farelo de soja e raiz de mandioca; FTMa: farelo de trigo e raiz de mandioca; FSMiSD: farelo de soja e milho semiduro; FSMiD: farelo de soja e milho dentado.

${ }^{2} \mathrm{NRC}(2001)$.

${ }^{3} \mathrm{~g} / \mathrm{kg}$ de matéria natural.

${ }^{4} \mathrm{~g} / \mathrm{kg}$ de matéria seca.

${ }^{5} 10 \mathrm{~g}$ de ureia/kg de matéria natural.

Fonte: Elaboração dos autores. 
As dietas foram pré-secas em estufa de ventilação forçada a $60{ }^{\circ} \mathrm{C}$ por $72 \mathrm{~h}$. Depois, foram moídas em moinho mecânico com peneira de $1 \mathrm{~mm}$ para determinação da matéria seca (MS) em estufa a $105^{\circ} \mathrm{C}$, proteína bruta (PB), extrato etéreo (EE) e matéria mineral (MM) de acordo com os padrões da AOAC (1995), e componentes da parede celular pelo método de detergentes (GOERING; VAN SOEST, 1970). Os carboidratos totais (CHOT) foram obtidos por intermédio da equação 100 - (\% $\mathrm{PB}+\% \mathrm{EE}+\% \mathrm{MM})$ descrita por Sniffen et al. (1992). Os carboidratos não fibrosos (CNF) foram calculados como segue: $\mathrm{CNF}=100-[(\mathrm{PB}-\mathrm{PBu}+$ $\mathrm{U})+\mathrm{EE}+\mathrm{MM}+\mathrm{FDNcp}]$ descrita por Hall (2000) em que: $\mathrm{PBu}$ corresponde ao teor de $\mathrm{PB}$ proveniente da ureia (\%); U corresponde a teor de ureia (\%); e que FDNcp corresponde à fração FDN corrigida para o conteúdo analisado da matéria mineral e nitrogênio multiplicado pelo fator 6,25. Para estimar o teor de nutrientes digestíveis totais (NDT) das dietas foram utilizadas as equações propostas por Weiss (1993), com as modificações sugeridas pelo NRC (2001):

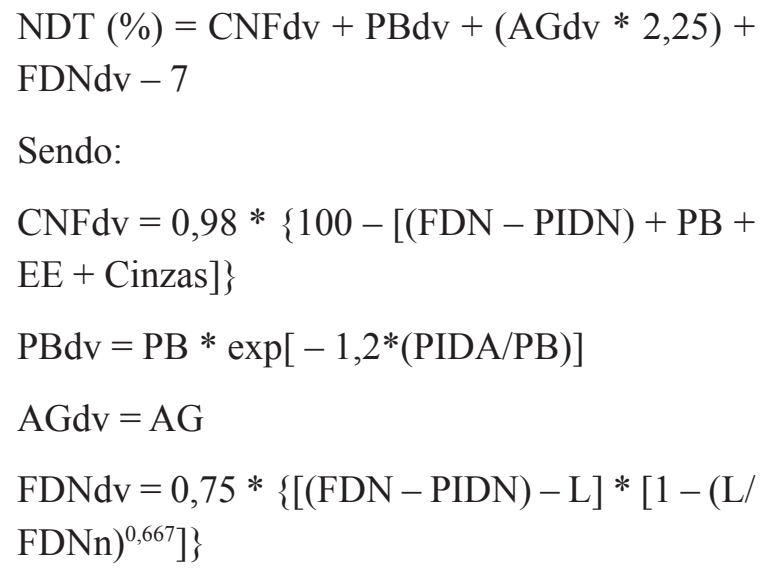

Em que: $\mathrm{CNFdv}=$ carboidratos não-fibrosos verdadeiramente digestíveis; $\mathrm{PBdv}=$ proteína bruta verdadeiramente digestível; $\mathrm{AGdv}=$ ácidos graxos verdadeiramente digestíveis e FDNdv = fibra em detergente neutro verdadeiramente digestível; FDN = fibra em detergente neutro; PIDN = proteína insolúvel em detergente neutro; $\mathrm{PB}=$ proteína bruta; $\mathrm{EE}=$ extrato etéreo; $\mathrm{AG}=$ ácidos graxos, nos quais $\mathrm{AG}=\mathrm{EE}-1 ; \mathrm{FDNn}=\mathrm{FDN}$ corrigido para a proteína; PIDA = proteína insolúvel em detergente ácido; L = lignina; o fator 7 refere-se ao NDT recuperado nas fezes. Os tratamentos e as respectivas composições bromatológicas podem ser encontrados na Tabela 1.

As dietas foram incubadas em frascos $(160 \mathrm{~mL})$, previamente injetados com $\mathrm{CO}_{2}$ segundo a técnica in vitro semi-automática de produção de gases descrita por Maurício et al. (1999). Para tanto, os frascos foram colocados em uma estufa com temperatura constante de $39^{\circ} \mathrm{C}$ durante todo o período de incubação. Foi adicionado $1,0 \mathrm{~g}$ de amostra por frasco para cada tratamento (matéria natural), juntamente, 90,0 mL de meio de cultura conforme Theodorou et al. (1994) e, em seguida, estes foram vedados com rolhas de borracha. A inoculação (10,0 $\mathrm{mL} /$ frasco) foi feita usando líquido ruminal de três bovinos fistulados no rúmen e mantidos a pasto (Brachiaria sp.), sendo cada animal considerado um bloco e uma mistura homogenia desses três inóculos originou o quarto bloco.

A produção cumulativa de gases foi estimada por meio da mensuração da pressão dos gases produzidos no decorrer do processo fermentativo, utilizando-se um transdutor de pressão (tipo T443A; BAILEY; MACKEY, Inglaterra), às 2, 4, $6,8,10,12,15,18,21,24,30,36,48,72$ e $96 \mathrm{~h}$ de incubação fazendo-se uso da equação determinada por Figueiredo et al. (2003) para altitude local, V = $-0,02+4,30 p+0,07 p^{2}, R^{2}=0,99$, onde $V=$ volume total de gases e "p" é a pressão dos gases dentro dos frascos de fermentação (psi = pressão por polegada quadrada). De cada leitura de pressão, foi subtraído o total produzido pelos frascos sem substrato (branco), referentes a cada amostra.

Nos tempos de fermentação 6, 12, 24, 48 e 96 horas, dois frascos por tratamento foram retirados, procedendo-se a filtração do primeiro para a determinação da degradabilidade aparente da 
matéria seca. No segundo, foi realizada a digestão em detergente neutro do incubado remanescente da fermentação (GOERING; VAN SOEST, 1970), obtendo-se a degradabilidade verdadeira.

A biomassa microbiana ( $\mathrm{g} / \mathrm{kg}$ de MS digestível) foi mensurada a partir da diferença entre o substrato aparentemente degradado e o verdadeiramente degradado (BLUMMEL; MAKKAR; BECKER, 1997).

O modelo bicompartimental proposto por Schofield, Pitt e Pell (1994) foi utilizado para descrever a cinética do processo de fermentação por meio da produção cumulativa de gases como se segue:

$$
\begin{aligned}
& \mathrm{V}(\mathrm{t})=(\mathrm{Vf} 1 /(1+\exp (2-4 * \mathrm{Kd} 1 *(\mathrm{~T}-\mathrm{L})))+ \\
& (\mathrm{Vf} 2 /(1+\exp (2-4 * \mathrm{Kd} 2 *(\mathrm{~T}-\mathrm{L})))
\end{aligned}
$$

onde, $\mathrm{V}(\mathrm{t})$ é o volume acumulado no tempo t; Vf1 (mL/g), o volume de gás oriundo da fração de rápida digestão $(\mathrm{CNF}) ; \mathrm{Kd} 1(1 / \mathrm{h})$, a taxa de degradação da fração de rápida digestão $(\mathrm{CNF})$; $\mathrm{L}$, latência ou tempo de colonização em horas; T (h), o tempo de incubação; Vf2 (mL/g), o volume de gás da fração de lenta degradação (B2); Kd2 (1/h), taxa de degradação da fração B2.

Determinou-se o fator de partição (FP), obtido pela divisão dos valores do substrato verdadeiramente degradado $(\mathrm{g} / \mathrm{kg})$ pela produção de gases $(\mathrm{mL})$, em cada tempo de degradação (BLUMMEL; MAKKAR; BECKER, 1997; BLUMMEL et al., 1999), para comparar as quatro dietas em relação as suas eficiências de degradação e produção de gases.

O delineamento experimental foi o de blocos inteiramente ao acaso, analisado como parcelas subdivididas para a comparação dos parâmetros nas horas de incubação, adotando-se para formação de blocos as fontes dos inóculos. As parcelas foram constituídas pelas dietas (FSMa, FTMa, FSMiSD e FSMiD) e as subparcelas pelos tempos de incubação. Para comparação das médias das dietas, nos tempos de fermentação, utilizou-se o teste SNK $(\mathrm{P}<0,05)$. Foi realizada a análise de regressão entre a produção de gases e resultados de degradabilidade verdadeira, a estimativa para os parâmetros do modelo bicompartimental foram obtidos a partir do uso do método Gauss-Newton, dentro do PROC NLIN, com o auxílio do programa Statistical Analyses System - SAS (SAS, 2002).

\section{Resultados e Discussão}

$\mathrm{Na}$ Tabela. 2 encontram-se as produções cumulativas de gases e as degradabilidades verdadeiras da matéria seca das dietas com diferentes fontes de amido, no decorre das 96 horas de fermentação ruminal in vitro.

As dietas que continham mandioca na sua composição apresentaram produções cumulativas de gases (PCG) maiores nas primeiras horas de incubação quando comparadas com as com milho. Assim, no período inicial de seis horas de incubação a dieta FTMa $(28,9 \mathrm{~mL} / \mathrm{g})$ foi superior às demais $(\mathrm{P}<0,05)$ enquanto que, às 12 horas, a dieta FSMa $(86,4 \mathrm{~mL} / \mathrm{g})$ mostrouse superior a todas as outras $(\mathrm{P}<0,05)$ e as dietas FSMiSD $(51,8 \mathrm{~mL} / \mathrm{g})$ e FSMiD $(52,5 \mathrm{~mL} / \mathrm{g})$ não diferiram $(\mathrm{P}>0,05)$, quando apresentaram as menores produções neste tempo de incubação. Ela contribui também para o aumento da produção de ATP, necessário ao crescimento microbiano favorecendo o atendimento das necessidades de proteína dos ruminantes. Em conjunto com os gases mensurados, são também produzidos ácidos graxos voláteis (AGV), que são utilizados pelos ruminantes como fonte de energia.

Ainda, até às 24 horas de incubação, a dieta FSMa apresentou maior PCG $(\mathrm{P}<0,05)$, quando as dietas contendo milho ou trigo não diferiram entre si $(\mathrm{P}>0,05)$. Nas 48 horas após o início da fermentação, a PCG da dieta contendo farelo de 
trigo (FTMa) foi inferior às demais $(\mathrm{P}<0,05)$. Ao final do período de incubação, a produção total de gases às 96 horas foi menor para a dieta FTMa e maior para o FSMiSD diferindo a $(\mathrm{P}<0,05)$, variando de $228,9 \mathrm{~mL} / \mathrm{g}$ a $270,2 \mathrm{~mL} / \mathrm{g}$ respectivamente. Observa-se que não houve diferença $(\mathrm{P}>0,05)$ para as dietas FSMa e a dieta FSMiD. Ao mesmo tempo, a dieta FSMiSD não diferiu da FSMiD na produção de gases às 96 horas.

Avaliando as PCG entre as dietas nos diferentes períodos de fermentação observa-se que apesar de as dietas serem compostas por frações similares de carboidratos totais, os resultados das PCG que refletem a natureza do processo fermentativo foram bastante heterogêneos.

A PCG da dieta contendo exclusivamente mandioca como fonte de amido na sua composição (FSMa) foi superior às demais nas primeiras 24 horas, de incubação $(193,7 \mathrm{~mL} / \mathrm{g})$. Esta superioridade na PCG nesta dieta, em relação às outras contendo milho ou trigo, se refletiu no resultado de DVMS $(858,80 \mathrm{~g} / \mathrm{kg}$ de matéria seca), que foi maior que as outras ( $\mathrm{P}<0,05$; Tabela 2).

Tabela 2. Produções cumulativas de gases (PCG) e degradabilidades verdadeiras da MS (DVMS), das dietas.

\begin{tabular}{cccccc}
\hline \multirow{2}{*}{ Dietas $^{1}$} & \multicolumn{5}{c}{ Períodos de fermentação (horas) } \\
\cline { 2 - 6 } & 6 & 12 & 24 & 48 & 96 \\
\cline { 2 - 5 } FSMa & $22,6 \mathrm{~b}$ & $86,4 \mathrm{a}$ & $193,7 \mathrm{a}$ & $238,8 \mathrm{a}$ & $254,4 \mathrm{~b}$ \\
FTMa & $28,9 \mathrm{a}$ & $75,4 \mathrm{~b}$ & $164,2 \mathrm{~b}$ & $208,8 \mathrm{~b}$ & $228,9 \mathrm{c}$ \\
FSMiSD & $20,4 \mathrm{~b}$ & $51,8 \mathrm{c}$ & $159,0 \mathrm{~b}$ & $244,4 \mathrm{a}$ & $270,2 \mathrm{a}$ \\
FSMiD & $21,4 \mathrm{~b}$ & $52,5 \mathrm{c}$ & $158,7 \mathrm{~b}$ & $238,4 \mathrm{a}$ & $262,3 \mathrm{ab}$ \\
\hline & \multicolumn{5}{c}{ DVMS $(\mathrm{g} / \mathrm{kg})$} \\
FSMa & $682,90 \mathrm{a}$ & $749,40 \mathrm{a}$ & $858,80 \mathrm{a}$ & $902,30 \mathrm{a}$ & $917,50 \mathrm{~b}$ \\
FTMa & $598,10 \mathrm{~b}$ & $672,45 \mathrm{~b}$ & $781,08 \mathrm{c}$ & $845,55 \mathrm{~b}$ & $872,45 \mathrm{c}$ \\
FSMiSD & $563,45 \mathrm{~b}$ & $616,60 \mathrm{~b}$ & $816,45 \mathrm{~b}$ & $907,95 \mathrm{a}$ & $926,60 \mathrm{ab}$ \\
FSMiD & $587,35 \mathrm{~b}$ & $596,38 \mathrm{~b}$ & $805,63 \mathrm{~b}$ & $918,90 \mathrm{a}$ & $940,90 \mathrm{a}$ \\
\hline
\end{tabular}

Valores seguidos por letras distintas na coluna diferem entre si pelo teste $\mathrm{SNK}$ a $5 \%$ de probabilidade $(\mathrm{P}<0,05)(\mathrm{PCG}$ : $\mathrm{CV}=7,91 \%$; DVMS: $\mathrm{CV}=2,93 \%$ ).

${ }^{1}$ FSMa: farelo de soja e raiz de mandioca; FTMa: farelo de trigo e raiz de mandioca; FSMiSD: farelo de soja e milho semiduro; FSMiD: farelo de soja e milho dentado.

Fonte: Elaboração dos autores.

Nas 24 horas de incubação iniciais, a dieta FSM apresentou maior PCG e DVMS (valores $\mathrm{mL}$ e $\mathrm{mg}$ respectivamente; Tabela 2) quando comparada com as outras, inclusive a FTMa, que continha mandioca. A dieta FSMa apresentou maior DVMS $(858,80 \mathrm{~g} / \mathrm{kg}$ de matéria seca) que as dietas FSMiD $(805,63 \mathrm{~g} / \mathrm{kg}$ de matéria seca) e FSMiSD $(816,45$ $\mathrm{g} / \mathrm{kg}$ de matéria seca), que foram semelhantes estatisticamente entre si e superiores a dieta FTMa $(781,08 \mathrm{~g} / \mathrm{kg}$ de matéria seca) $(\mathrm{P}<0,05)$. Após 48 horas, a dieta FTMa foi inferior estatisticamente quando comparado às demais dietas e estas foram semelhantes $(\mathrm{P}>0,05)$.

A DVMS ao final da fermentação (96 horas) para a dieta FTMa foi inferior às demais $(\mathrm{P}<0,05)$. Já a dieta FSMa apresentou menor DVMS quando comparado à da dieta FSMiD $(\mathrm{P}<0,05)$, porém foi estatisticamente semelhante à dieta FSMiSD. Os diferentes genótipos de milho não diferiram entre si $(\mathrm{P}>0,05)$.

Wascheck et al. (2010) ao avaliarem a produção 
de gases in vitro de dietas que continham $55 \%$ de volumoso (silagem de sorgo + ureia) e 45\% de concentrado da MS da dieta total (farelo de arroz parboilizado, farelo de arroz integral, fubá de milho e suas associações), observaram que a dieta que continha $100 \%$ de fubá de milho apresentou maior produção cumulativa de gases $(\mathrm{P}<0,05)$ a partir de $24 \mathrm{~h}$, ratificando uma menor produção de gases nas primeiras horas de incubação, em consonância com o observado neste trabalho.

Nas 48 horas de incubação, as dietas que continham milho como fonte de amido nos concentrados igualaram-se na produção cumulativa de gases à dieta que continha mandioca. Este período é considerado limite para a permanência de grãos no rúmen para vacas em lactação com taxa de passagem de $4 \% / \mathrm{h}$ a $6,5 \% / \mathrm{h}$. As produções de gases semelhantes para o milho e mandioca indicam a existência de disponibilidade de energia fermentável no rúmen disponível à microbiota ruminal (NOCEK, 1988).

Zeoula et al. (1999) ao avaliarem os teores de amido de diferentes alimentos encontraram para o milho, sorgo, raspa de mandioca e farelo de trigo, respectivamente, 793; 834; 914; $491 \mathrm{~g} / \mathrm{kg}$ de matéria seca. Os mesmos autores encontraram para a solubilidade (fração a) do amido de milho, sorgo, raspa de mandioca, farelo de trigo observaram-se os valores de $184 ; 521 ; 520 ; 873 \mathrm{~g} / \mathrm{kg}$, respectivamente.

A proporção de amido e sua solubilidade interferem na degradação dos alimentos, sendo que quanto maior for à quantidade de amido maior será a degradação do alimento. Assim, quando este polímero apresenta alta solubilidade, mais rápida será também está degradação em nível ruminal. Este aspecto foi evidenciado por Caldas Neto et al. (2007) que testaram dietas com níveis crescentes de proteína degradável no rúmen, associada à fonte de amido de alta degradabilidade ruminal (farinha de varredura de mandioca). Foi observada interação entre proteína degradável no rúmen e a fonte de amido de alta degradabilidade ruminal (raiz integral de mandioca) que se destacou das demais fontes que apresentavam uma degradabilidade ruminal inferior.

Van Amburgh et al. (2012) comparando o sistema CNCPS versão 6.1 com o anterior ressaltaram que a taxa de degradação para a fração A do nitrogênio (NNP) foi atualizada de $10.000 \% / \mathrm{h}$ para $200 \% / \mathrm{h}$, mesmo com essa redução essa fração ainda apresenta uma taxa de DVMS superior as demais $(\mathrm{B} 1=10$ 40; B2 = 3 - 20; B3 = 4 - 9 e $\mathrm{C}=0$ ) o que implica na necessidade de uma fonte de carboidrato que apresente uma elevada taxa de degradação para uma maior sincronização entre os nutrientes fornecidos pela dieta.

Nogueira, Mauricio e Gonçalves (2006) avaliaram a fermentação in vitro de grão de milho e concentrado comercial pela técnica semi-automática de produção de gases em que se encontrou às $96 \mathrm{~h}$ uma PCG de $301 \mathrm{~mL} / \mathrm{g}$ e $379 \mathrm{~mL} / \mathrm{g}$ respectivamente. Estes valores estão próximos aos mensurados neste trabalho considerando-se que as dietas nos dois experimentos continham altos teores de carboidratos que é a principal fonte para a produção de gases.

A maior produção de gases está relacionada a uma maior fermentação dos carboidratos, que apresenta elevada correlação (Tabela 3). O modelo de regressão linear foi o que melhor descreveu a relação entre a degradabilidade verdadeira da matéria seca e produção de gases, ao longo do tempo de incubação, em todas as dietas avaliadas evidenciando a elevada correlação entre a produção de gases e a degradação da matéria seca (MAURÍCIO et al., 2003). 
Tabela 3. Relação entre a produção de gases e a degradabilidade verdadeira da matéria seca das dietas com diferentes fontes de amido foi descrito pelas seguintes equações de regressão.

\begin{tabular}{clcc}
\hline Dietas $^{1}$ & \multicolumn{1}{c}{ Equações $^{2}$} & $\mathrm{R}^{2}$ & $\mathrm{P}$ \\
\hline FSMa & DVMS $_{\mathrm{n}}(\mathrm{g} / \mathrm{kg})=1,0087 \mathrm{PG}_{\mathrm{n}}+661,60$ & $\left(\mathrm{R}^{2}=0,99\right)$ & $\mathrm{P}<0,01$ \\
FTMa & DVMS $_{\mathrm{n}}(\mathrm{g} / \mathrm{kg})=1,3452 \mathrm{PG}_{\mathrm{n}}+564,55$ & $\left(\mathrm{R}^{2}=0,98\right)$ & $\mathrm{P}<0,01$ \\
FSMiSD & DVMS $_{\mathrm{n}}(\mathrm{g} / \mathrm{kg})=1,4821 \mathrm{PG}_{\mathrm{n}}+545,11$ & $\left(\mathrm{R}^{2}=0,91\right)$ & $\mathrm{P}<0,01$ \\
FSMiD & DVMS $_{\mathrm{n}}(\mathrm{g} / \mathrm{kg})=1,5726 \mathrm{PG}_{\mathrm{n}}+539,21$ & $\left(\mathrm{R}^{2}=0,94\right)$ & $\mathrm{P}<0,01$ \\
\hline
\end{tabular}

${ }^{1}$ FSMa:farelo de soja e raiz de mandioca; FTMa: farelo de trigo e raiz de mandioca; FSMiSD: farelo de soja e milho semiduro; FSMiD: farelo de soja e milho dentado.

${ }^{2}$ DVMS $=$ degradabilidade verdadeira da matéria seca no período $\mathrm{n}$ (horas) de fermentação $(\mathrm{g} / \mathrm{kg})$ e $\mathrm{PG}=$ produção de gases no período $\mathrm{n}$ (horas) de fermentação $(\mathrm{mL})$.

Fonte: Elaboração dos autores.

A evolução das produções cumulativas e não cumulativas de gases nas dietas podem ser observadas nas Figuras 1 e 2 respectivamente. Na Figura 1 podem ser observadas as curvas de produção cumulativa de gases, obtidas para as dietas experimentais em que a dieta FTMa apresentou a menor produção ao final de $96 \mathrm{~h}$. Verifica-se que, entre as 30 horas e 48 horas de fermentação, as curvas de produção cumulativa de gases apresentam decréscimo na produção de gases, mostrando uma tendência de estabilização após às 48 horas de fermentação. Na Figura 2, observa-se que as maiores taxas de produção de gases por hora foram obtidas, para todas as dietas, aproximadamente após três horas de fermentação, fato provavelmente ligado à fermentação dos carboidratos prontamente disponíveis. Entre os tempos de fermentação de, aproximadamente, 6 às 8 horas, observou-se uma segunda elevação na taxa de produção de gases por hora para as dietas FSMa e FTMa enquanto que, para as dietas FSMiSD e FSMiD, esta elevação ocorreu das 12 às 18 horas. Nestas últimas, houve um decréscimo mais lento nesta taxa de produção quando comparado às duas primeiras. Este segundo incremento na produção não cumulativa de gases está relacionado provavelmente à fermentação dos carboidratos fibrosos.

Os parâmetros da cinética da fermentação ruminal ajustados pelo modelo bicompartimental estão apresentados na Tabela 4. Para o parâmetro Vf1, que indica a produção de gases das frações de carboidratos não fibrosos da dieta, os tratamentos contendo as duas variedades de milho (FSMiSD e FSMiD) não diferiram entre si $(\mathrm{P}>0,05)$. Entretanto, o tratamento FSMiSD $(184,28 \mathrm{~mL} / \mathrm{g})$ diferiu $(\mathrm{P}<0,05)$ do FSMa e do FTMa $(149,56$ $\mathrm{mL} / \mathrm{g}$ e $135,34 \mathrm{~mL} / \mathrm{g}$, respectivamente) indicando que ao longo do período de incubação estudado a menor taxa de produção de gases mensurada nesta dieta contendo milho foi compensada por uma fermentação in vitro mais duradoura, que se refletiu em uma produção mais elevada de gases ao final do período (Figura 1). A produção de gases referente ao parâmetro Vf1 do FTMa diferiu $(\mathrm{P}<0,05)$ das dietas que continham milho como fonte principal de amido, uma vez que apresentou menor produção de gases do que as dietas FSMiSD e FSMiD.

Por outro lado, as taxas de produção de gases das frações de carboidratos não fibrosos $(\mathrm{Kd} 1)$ foram maiores nas dietas FSMa e FTMa, indicando que as diferenças nas composições dos carboidratos nestas dietas influenciaram as produções de gases, embora tenham apresentado valores absolutos menores nestas dietas, foram produzidas a taxas maiores quando comparada às das dietas contendo milho. Isto indica que a degradação dos carboidratos não fibrosos contidos nestas dietas foi realizada a maiores velocidades que as daquelas contendo milho, permitindo a possibilidade de serem disponibilizadas mais rapidamente para os microrganismos do rúmen. 
Figura 1. Curvas de produção cumulativa de gases em quatro dietas contendo diferentes fontes de amido.

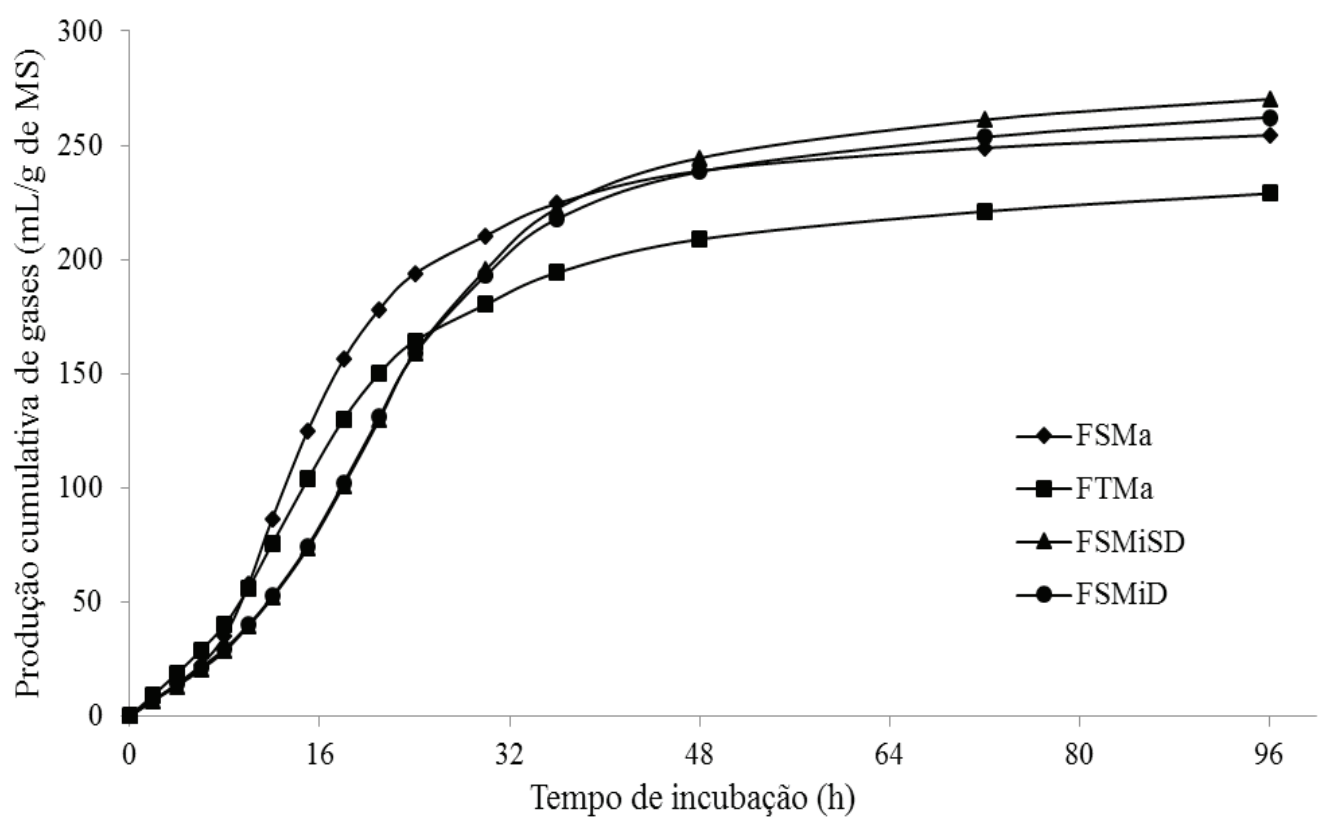

Fonte: Elaboração dos autores.

Figura 2. Evolução da produção não cumulativa de gases em quatro dietas contendo diferentes fontes de amido.

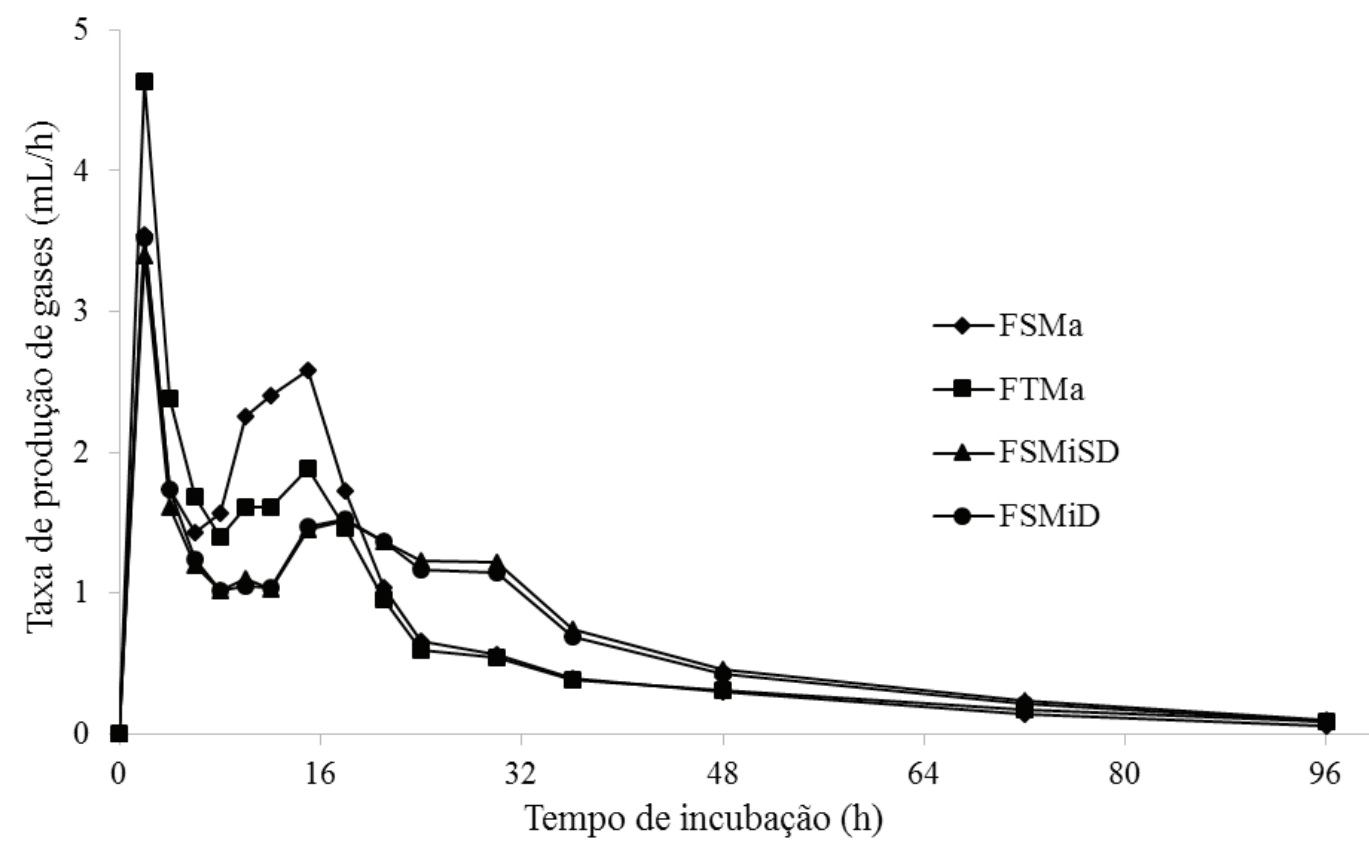

Fonte: Elaboração dos autores. 
Tabela 4. Estimativa dos parâmetros cinéticos da produção de gases in vitro da matéria seca (MS) das dietas.

\begin{tabular}{|c|c|c|c|c|c|}
\hline \multirow{2}{*}{ Parâmetros ${ }^{2}$} & \multicolumn{4}{|c|}{ Tratamentos $^{1}$} & \multirow{2}{*}{ CV $(\%)$} \\
\hline & FSMa & FTMa & FSMiSD & FSMiD & \\
\hline $\mathrm{Vf1}(\mathrm{mL} / \mathrm{g})$ & $149,56 b c$ & $135,34 \mathrm{c}$ & $184,28 \mathrm{a}$ & $175,16 a b$ & 10,07 \\
\hline Kd1 (1/h) & $0,09 a$ & $0,07 \mathrm{~b}$ & $0,05 c$ & $0,051 \mathrm{c}$ & 5,89 \\
\hline $\mathrm{L}(\mathrm{h})$ & $7,18 \mathrm{~b}$ & $5,95 \mathrm{c}$ & $9,09 a$ & $8,65 \mathrm{a}$ & 6,42 \\
\hline $\mathrm{Vf2}(\mathrm{mL} / \mathrm{g})$ & $101,35 \mathrm{a}$ & $90,15 a$ & $84,02 \mathrm{a}$ & $84,92 a$ & 15,56 \\
\hline $\mathrm{Kd} 2(1 / \mathrm{h})$ & $0,026 \mathrm{a}$ & $0,021 b$ & $0,019 b$ & $0,02 b$ & 9,9 \\
\hline Total $(\mathrm{mL} / \mathrm{g})$ & $250,91 b$ & $225,49 \mathrm{c}$ & $268,31 \mathrm{a}$ & $260,08 \mathrm{ab}$ & 2,48 \\
\hline
\end{tabular}

Valores seguidos por letras distintas na linha diferem entre si pelo teste SNK a $5 \%$ de probabilidade $(\mathrm{P}<0,05)$

${ }^{1}$ FSMa: farelo de soja e raiz de mandioca; FTMa: farelo de trigo e raiz de mandioca; FSMiSD: farelo de soja e milho semiduro; FSMiD: farelo de soja e milho dentado.

${ }^{2}$ Parâmetros: Vfl: volume máximo de produção de gases da fração CNF; Kd1: taxa de digestão para a fração dos CNF; L: tempo de colonização; Vf2: volume máximo da produção de gases da fração dos CF; Kd2: taxa de digestão para a fração dos CF.

Fonte: Elaboração dos autores.

Em conformidade com a maior taxa de degradação, os tempos de colonização (L) na tabela 4 estimados pelo modelo matemático foram menores $(\mathrm{P}<0,05)$ nas dietas contendo mandioca, quando comparado às outras duas (milho), que apresentaram maior tempo para colonização. O menor tempo de colonização encontrado para o tratamento FTMa se deve provavelmente as diferenças entre as fontes de amido, relacionada ao fato de o farelo de trigo que compõe a dieta apresentar alta fração solúvel (ZEOULA et al., 1999).

A maior degradabilidade e digestibilidade do amido da mandioca comparado ao amido do milho e de outros grãos de cereais se deve as diferenças nas suas composições (CALDAS NETO et al., 2000). Essa superioridade provavelmente está associada à estrutura dos grânulos de amido desse alimento, que apresentam elevado conteúdo de amilopectina e ausência de associação dos grânulos de amido com a matriz proteica (PIRES, 1999). O grão de milho apresenta uma matriz proteica formada por zeínas que recobrem o amido sendo que essa matriz interfere negativamente na velocidade de degradação ruminal (LARSON; HOFFMAN, 2008).

A produção total de gases (Tabela 4) foi menor para a dieta FTMa e maior para o FSMiSD, variando de $225,49 \mathrm{~mL} / \mathrm{g}$ a $268,31 \mathrm{~mL} / \mathrm{g}$, respectivamente. Estatisticamente, os resultados foram semelhantes aos obtidos para o parâmetro Vfl diferindo apenas para a dieta FSMa que foi superior $(\mathrm{P}<0,05)$ a dieta FTMa.

Ao mesmo tempo, é interessante notar que a dieta com inclusão do milho semiduro, embora tenha apresentado velocidade de degradação menor do que a encontrada para as dietas FSMa e FTMa, não diferiu do milho dentado na produção total de gases, tampouco na velocidade de degradação das duas frações de carboidratos.

As produções de gases obtidas pelo modelo de Schofield, Pitt e Pell (1994) nas frações de carboidratos não fibrosos e fibrosos separadamente, estão apresentadas na Figura 3. 
Figura 3. Curvas de produção cumulativa de gases proveniente dos A (carboidratos não fibrosos) e B (carboidratos fibrosos) em quatro dietas contendo diferentes fontes de amido.

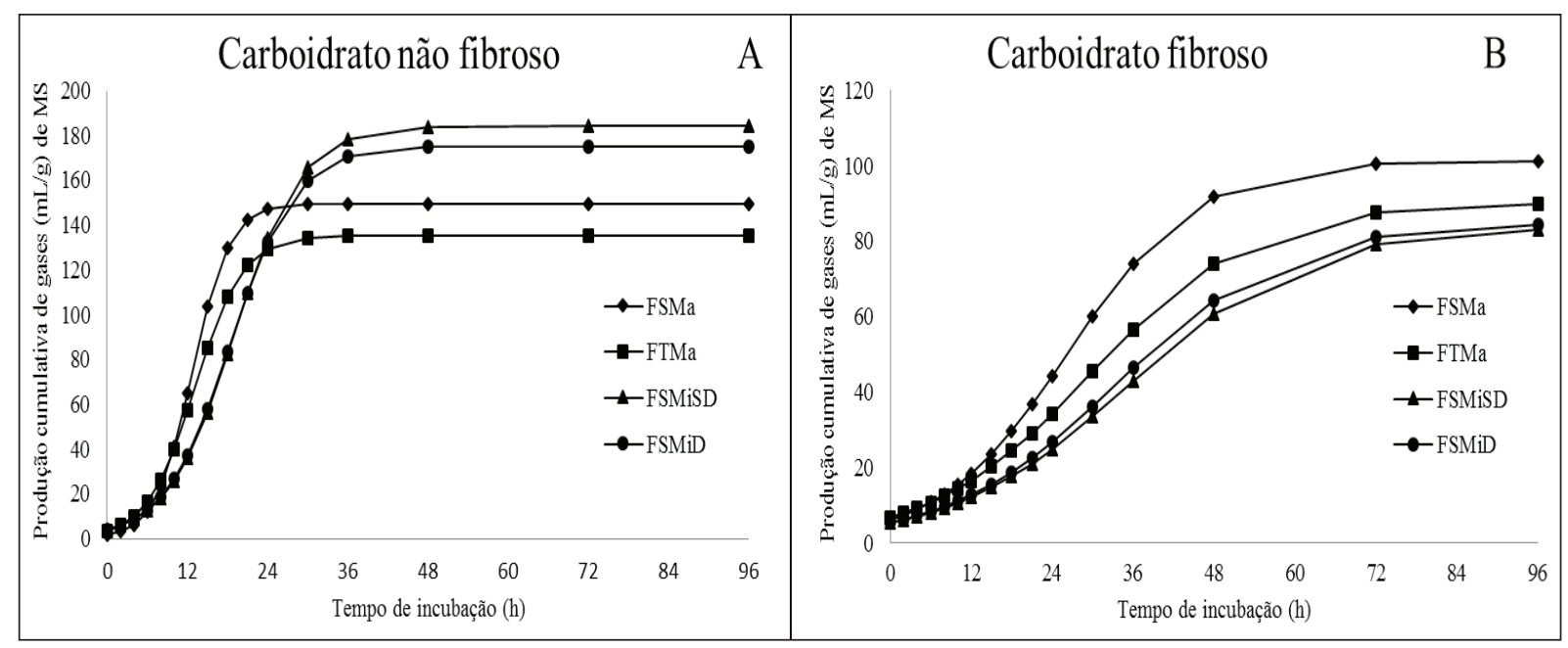

Fonte: Elaboração dos autores.

Com relação à biomassa microbiana observouse que, às seis horas de incubação, a dieta FTMa foi inferior $(\mathrm{P}<0,05)$ as demais que não diferiram ente si $(\mathrm{P}>0,05)$. Já às 12 horas de incubação in vitro não foi encontrada diferença significativa para os valores de $\mathrm{BIO}$, que variaram de $248,5 \mathrm{~g} / \mathrm{kg}$ a $305,7 \mathrm{~g} / \mathrm{kg}$ de substrato degradado. No período de 24 a 96 horas de incubação, as dietas contendo milho apresentaram produções de BIO maiores que as outras duas, contendo mandioca quando, ao final do período, as primeiras superaram $100 \mathrm{~g} / \mathrm{kg}$ enquanto que, as últimas não atingiram este patamar (Tabela 5).

Tabela 5. Valores médios de biomassa microbiana (BIO), e fator de partição (FP) às 6, 12, 24, 48 e 96 horas de fermentação das dietas.

\begin{tabular}{cccccc}
\hline \multirow{2}{*}{ Dietas $^{1}$} & \multicolumn{5}{c}{ Períodos de fermentação } \\
\cline { 2 - 6 } & 6 & 12 & 24 & 48 & 96 \\
\cline { 2 - 6 } FSMa & $369,61 \mathrm{a}$ & $261,51 \mathrm{a}$ & $125,98 \mathrm{~b}$ & $52,49 \mathrm{c}$ & $67,94 \mathrm{~b}$ \\
FTMa & $267,73 \mathrm{~b}$ & $248,49 \mathrm{a}$ & $161,16 \mathrm{~b}$ & $85,88 \mathrm{~b}$ & $84,38 \mathrm{~b}$ \\
FSMiSD & $365,16 \mathrm{a}$ & $305,66 \mathrm{a}$ & $247,32 \mathrm{a}$ & $130,95 \mathrm{a}$ & $116,11 \mathrm{a}$ \\
FSMiD & $340,53 \mathrm{a}$ & $280,80 \mathrm{a}$ & $226,13 \mathrm{a}$ & $132,61 \mathrm{a}$ & $115,21 \mathrm{a}$ \\
\hline & \multicolumn{5}{c}{ FP $(\mathrm{mg} / \mathrm{mL})$} \\
FSMa & $30,24 \mathrm{a}$ & $8,69 \mathrm{~b}$ & $4,44 \mathrm{~b}$ & $3,78 \mathrm{ab}$ & $3,61 \mathrm{~b}$ \\
FTMa & $20,80 \mathrm{~b}$ & $8,93 \mathrm{~b}$ & $4,77 \mathrm{ab}$ & $4,05 \mathrm{a}$ & $3,82 \mathrm{a}$ \\
FSMiSD & $27,95 \mathrm{a}$ & $12,02 \mathrm{a}$ & $5,17 \mathrm{a}$ & $3,71 \mathrm{~b}$ & $3,43 \mathrm{~b}$ \\
FSMiD & $27,61 \mathrm{a}$ & $11,36 \mathrm{a}$ & $5,09 \mathrm{a}$ & $3,85 \mathrm{ab}$ & $3,59 \mathrm{~b}$ \\
\hline
\end{tabular}

Valores seguidos por letras distintas na coluna diferem entre si pelo teste $\mathrm{SNK}$ a $5 \%$ de probabilidade $(\mathrm{P}<0,05)(\mathrm{BIO}: \mathrm{CV}=14,15 \%$; FP: $\mathrm{CV}=19,33 \%)$.

${ }^{1}$ FSMa:farelo de soja e raiz de mandioca; FTMa: farelo de trigo e raiz de mandioca; FSMiSD: farelo de soja e milho semiduro; FSMiD: farelo de soja e milho dentado.

Fonte: Elaboração dos autores. 
A dieta FTMa apresentou fator de partição menor que as dietas contendo milho nas primeiras 12 horas de fermentação $(\mathrm{P}<0,05)$. Transcorridas 24 horas de fermentação, a dieta FSMa apresentou menor FP quando comparado às dietas FSMiSD e FSMiD $(\mathrm{P}<0,05)$, porém foi estatisticamente semelhante à dieta FTMa. Entretanto às 48 horas, a tendência se inverte e os FP das dietas contendo mandioca superam as com milho. O comportamento verificado no período final de fermentação (96 horas) demonstra superioridade $(\mathrm{P}<0,05)$ para a dieta FTMa em relação às demais que foram semelhantes estatisticamente $(\mathrm{P}>0,05)$.

Os valores do fator de partição, que relacionam a quantidade de substrato verdadeiramente degradado $(\mathrm{g} / \mathrm{kg})$ e a produção de gases $(\mathrm{mL})$, diminuíram com o tempo de incubação entre as dietas avaliadas. Esse fato está associado à dinâmica de fermentação dos carboidratos não fibrosos que são degradados nas primeiras horas de fermentação e produzem menos gases em relação às carboidratos fibrosos (BLUMMEL; MAKKAR; BECKER, 1997).

Os substratos que apresentam elevada degradabilidade verdadeira, proporcionalmente a baixa produção de gases apresentam maior fator de partição, maior consumo de matéria seca, maior biomassa microbiana, mais alta eficiência na síntese de proteína microbiana, mais baixa produção de metano e mais baixa produção de AGV (BLUMMEL et al., 1999; MAKKAR, 2004).

Nogueira, Mauricio e Gonçalves (2006) avaliaram a fermentação in vitro da MS um concentrado comercial e do grão de milho pela técnica semi-automática de produção de gases encontraram um fator de partição elevado nas primeiras horas sendo que às 2 horas de incubação, observou-se os valores de $30,00 \mathrm{mg} / \mathrm{mL}$ e $23,08 \mathrm{mg} /$ $\mathrm{mL}$ para o milho integral e concentrado comercial integral, semelhantes aos descritos para as 6 horas (Tabela 5). Já para às 96 horas, observou-se os valores de $2,66 \mathrm{mg} / \mathrm{mL}$ e $2,89 \mathrm{mg} / \mathrm{mL}$ para o milho integral e concentrado comercial integral próximos portanto aos descritos neste trabalho (Tabela 5).

\section{Conclusões}

A utilização da mandioca como fonte de amido proporciona fermentação mais rápida do amido, quando comparada ao milho, permitindo melhor sincronismo com fontes de nitrogênio de rápida degradação, como a ureia. Os milhos dentado e semiduro apresentam maior degradação ao final de $96 \mathrm{~h}$ de incubação, porém a taxas de degradação inferiores às da mandioca e farelo de trigo.

\section{Referência}

ALBUQUERQUE, S. S. C.; LIRA, M. A.; SANTOS, M. V. F.; DUBEUX JÚNIOR, J. C. B.; MELO, J. N.; FARIAS, I. Utilização de três fontes de nitrogênio associadas à palma forrageira (Opuntia ficus-indica, Mill.) Cv. Gigante na suplementação de vacas leiteiras mantidas em pasto diferido. Revista Brasileira de Zootecnia, Viçosa, MG, v. 31, n. 3, p. 1315-1324, 2002.

ASSOCIATION OF OFFICIAL ANALYTICAL CHEMIST - AOAC. Internacional. Official methods of analisys. 16. ed. Washington, D.C., 1995.

BLUMMEL, M.; MAKKAR, H. P. S.; BECKER, K. In vitro gas production: a technique revisited. Journal of Animal Physiology and Nutrition, Oxford, v. 77, n. 1, p. 24-34, 1997.

BLUMMEL, M.; MGOMEZULU, R.; CHEN, X. B.; MAKKAR, H. P.; BECKER, K.; ØRSKOV, E. R. The modification of an in vitro gas production test to detect roughage related differences in vivo microbial protein synthesis as estimated by the excretion of purine derivatives. Journal of Agricultural Science, Cambridge, v. 133, n. 3, p. 335-340, 1999.

BODINE, T. N.; PURVIS II, H. T. Effects of supplemental energy and/or degradable intake protein on performance, grazing behavior, intake, digestibility, and fecal and blood indices by beef steers grazed on dormant native tallgrass prairie. Journal of Animal Science, Champaign, v. 81, n. 1, p. 304-317, 2003.

CALDAS NETO, S. F.; ZEOULA, L. M.; BRANCO, A. F.; PRADO, I. N.; SANTOS, G. T.; FREGADOLLI, F. L.; KASSIES, M. P.; DALPONTE, A. O. Mandioca e resíduos das farinheiras na alimentação de ruminantes: digestibilidade total e parcial. Revista Brasileira de Zootecnia, Viçosa, MG, v. 29, n. 6, p. 2099-2108, 2000. 
CALDAS NETO, S. F.; ZEOULA, L. M.; KAZAMA, R.; PRADO, I. N.; GERON, L. J. V.; OLIVEIRA, F. C. L.; PRADO, O. P. P. Proteína degradável no rúmen associada a fontes de amido de alta ou baixa degradabilidade: digestibilidade in vidro e desempenho de novilhos em crescimento. Revista Brasileira de Zootecnia, Viçosa, MG, v. 36, n. 2, p. 452-460, 2007.

FERREIRA, C. A.; FERREIRA, R. L. C.; SANTOS, D. C.; SANTOS, M. V. F.; SILVA, J. A. A.; LIRA, M. A.; MOLICA, S. G. Utilização de técnicas multivariadas na avaliação da divergência genética entre clones de palma forrageira (Opuntia ficus-indica Mill.). Revista Brasileira de Zootecnia, Viçosa, MG, v. 32, n. 6, p. 15601568, 2003.

FIGUEIREDO, M. P.; MAURICIO, R. M.; PEREIRA, L. G. R.; REBOUÇAS, G. M. N.; MOREIRA, G. R.; SOUSA, L. F. Determinação entre pressão e volume através da fermentação da raiz de mandioca tratada com ureia, feno de tifton 85 e silagem de milho para a instalação da técnica in vitro de produção de gás. In: REUNIÃO ANUAL DA SOCIEDADE BRASILEIRA DE ZOOTECNIA, 40., 2003, Santa Maria. Anais... Santa Maria. 2003. CD-ROM.

FREDRIKSSON, H., ANDERSSON, R., KOCH, K., AMAN, P. Calibration of a size-exclusion chromatography system using fractions with defined amylopectin unit chains. Journal of Chromatography A, Amsterdam, v. 768, n. 2, p. 325-328, 1997.

GOERING, H. K.; VAN SOEST, P. J. Forage fiber analysis (Apparatus, reagents, procedures, and some applications). Wasinhgton DC: ARS USDA, 1970. 20 p. (Agricutural Handbook, n. 379).

HALL, M. B. Neutral detergent-soluble carbohydrates. Nutritional relevance and analysis. Gainesville: University of Florida, 2000. 76 p.

LARSON, J.; HOFFMAN, P. C. Technical note: a method to quantify prolamin proteins in corn that are negatively related to starch digestibility in ruminants. Journal of Dairy Science, Madison, v. 91, n. 12, p. 4834-4839, 2008.

MAKKAR, H. P. S. Recent advances in the in vitro gas method for evaluation of nutritional quality of feed resources. In: Assessing quality and safety of animal feeds. Rome: Food and Agriculture Organization of the United Nations, 2004. p. 55-88. (FAO Animal Production and Health Paper, n. 160).

MAURÍCIO, R. M.; MOULD, F. L.; DHANOA, M. S.; OWEN, E.; CHANNA, K. S.; THEODOROU, M. K. A semi-automated in vitro gasesproduction technique for ruminants feedstuff evaluation. Animal Feed Science and Technology, Amsterdam, v. 79, n. 4, p. 321-330, 1999.
MAURÍCIO, R. M.; PEREIRA, L. G. R.; GONÇALVES, L. C.; RODRIGUEZ, N. M.; MARTINS, R. G. R.; RODRIGUES, J. A. S. Potencial da técnica in vitro semi-automática de produção de gases para avaliação de silagens de sorgo (Sorghum bicolor (L.) Moench). Revista Brasileira de Zootecnia, Viçosa, MG, v. 32, n. 4, p. 1013-1020, 2003.

MOORE, J. E.; BRANT, M. H.; KUNKLE, W. E.; HOPKINS, D. I. Effects of supplementation on voluntary forage intake, diet digestibility, and animal performance. Journal of Animal Science, Champaign, v. 77, p. 122135, 1999. Supplement 2.

NOCEK, J. E. In situ and others methods to estimate ruminal protein and energy digestibility: a review. Journal of Dairy Science, Madison, v. 71, n. 5, p. 20512069, 1988.

NOGUEIRA, U. T.; MAURÍCIO, R. M.; GONÇALVES, L. C. Comparação de substratos com diferentes quantidades de carboidratos solúveis utilizando a técnica in vitro semi-automática de produção de gases. Arquivo Brasileiro de Medicina Veterinária e Zootecnia, Belo Horizonte, v. 58, n. 4, p. 633-641, 2006.

NATIONAL RESEARCH COUNCIL - NRC. Nutrient requirements of beef cattle. 7. ed. Washington: National Academy Press, 1996. 242 p.

7. ed. Washington, D.C.: National

Academy Press, 2001. 408 p.

PIRES, A. V. Efeito da inclusão de fontes de amido e silagem de milho em dietas a base de cana-de-açúcar na digestibilidade de nutrientes e na produção de vacas holandesas. 1999. Tese (Livre-Docência). Escola Superior de Agricultura Luiz de Queiroz. Universidade de São Paulo, Piracicaba.

SCHOFIELD, P.; PITT, R. E.; PELL, A. N. Kinetics of fiber digestion from in vitro gas production. Journal of Animal Science, Champaign, v. 72, n. 11, p. 2980-2991, 1994.

SILVA, C. C. F. da; SANTOS, L. C. Palma forrageira (Opuntia fícus- indica Mill) como alternativa na alimentação de ruminantes. Revista Eletrônica de Veterinária REDVET ®, v.2, n. 10, out. 2006. Disponível em: $\quad<\mathrm{http}: / /$ www.veterinaria.org/revistas/redvet/ n101006/100609.pdf>. Acesso em: 25 ago. 2011.

SNIFFEN, C. J.; O'CONNOR, J. D.; VAN SOEST, P. J.; FOX, D. G. A net carbohydrate and protein system for evaluating cattle diets. 2. Carbohydrate and protein availability. Journal of Animal Science, Champaign, v. 70, n. 11, p. 3562-3577, 1992.

STATISTICAL ANALYSIS SYSTEM - SAS. Software, version 9.1.3 Cary: SAS Institute, 2002. 
THEODOROU, M. K.; WILLIAMS, B. A.; DHANOA, M. S.; MCALLAN, A. B. A simple gas production method using a pressure transducer to determine fermentation kinetics of ruminant feeds. Animal Feed Science Technology, Amsterdam, v. 48, n. 3-4, p. 185197, 1994.

VAN AMBURGH, M. E.; ROSS, D. A.; HIGGS, R. J.; RECKTENWALD, E. B.; CHASE, L. E. Balancing for rumen degradable protein and post-ruminal requirements for lactating cattle using the cncps as a basis for evaluation. In: ANNUAL FLORIDA RUMINANT NUTRITION SYMPOSIUM, 23., 2012, Gainesville, FL. Proceedings... Gainesville: UFL, 2012. p. 17-31.
WASCHECK, R. C.; REZENDE, P. L. P.; MOREIRA, P. C.; REIS, R. B.; DA ROSA, S. A.; MENDONÇA, A. C. Degradabilidade e produção de gases in vitro de fontes energéticas alternativas na alimentação de ruminantes. Acta Scientiarum. Animal Sciences, Maringá, v. 32, n. 4, p. 425-430, 2010.

WEISS, W. P. Predicting energy values of feeds. Journal of Dairy Science, Madison, v. 76, n. 6, p. 1802-1811, 1993.

ZEOULA, L. M.; MARTINS, A. S.; PRADO, I. N.; ALCALDE, C. R.; BRANCO, A. F.; SANTOS, G. T. Solubilidade e degradabilidade ruminal do amido de diferentes alimentos. Revista Brasileira de Zootecnia, Viçosa, MG, v. 28, n. 4, p. 898-905, 1999. 